\title{
Problemática dos Sistemas Administrativos
}

\section{SEMANTICA E PERSPECTIVAS DO SISTEMA DE PESSOAL CIVIL DA ADMINISTRAÇĀO FEDERAL}

ARAÚJO CAVALCANTI

Técnico de Administração. Diretor da Revista do Serviço Público

SUMARIO: I - Introdução. II - Temática dos Sistemas. III - Experiência Brasileira. IV - Conclusões.

\section{1 - INTRODUÇÃO}

\section{Advertência inicial}

A possibilidade de o Sistema de Pessoal Civil da Administração Federal funcionar como um dos fatôres dinâmicos do desenvolvimento planejado, integrado e auto-sustentado da Nação Brasileira é o objetivo das notas ora reunidas que 0 autor, desde já, reconhece incompletas e apressadas, carecendo de um tratamento mais sofisticado.

Valem, contudo, a intenção e o esfôrço de síntese dêstes ligeiros comentários ensejados pelo recente Decreto n: 67.326 , de 5-10-70, que, dando cumprimento a dispositivos do Decretolei no $200 / 67$, formalizou a organização daquele Sistema e tentou implantar uma mecânica de funcionamento adequada às atividades administrativas de pessoal do Serviço Civil do Poder Executivo.

São pontos de vista oriundos de uma breve consulta às fontes bibliográficas fundamentais que o autor entendeu de confrontar com as opiniöes de diversos administradores, chefes e assessôres de pessoal.

Através de contatos mantidos no decorrer do exercício de alguns cargos de direção e assessoramento com autoridades e técnicos diretamente preocupados com a problemática dos sis- 
temas administrativos, é tarefa simples pôr em relêvo algumas opiniões médias nascidas da observação e da vivência quotidiana, reflexos, portanto, de uma experiência pessoal válida a respeito de temas que, desde longa data, têm sido alvo do permanente interêsse dos administradores brasileiros.

Impõe-se esta advertência inicial a fim de que ninguém se decepcione desnecessàriamente, de vez que o autor não tem a veleidade de apresentar concepções originais nem, muito menos, qualquer "solução" definitiva e deseja, apenas, com tôda humildade e exata noção das suas notórias deficiências, motivar os mais entendidos, estimular os interessados e promover o indispensável debate - tanto mais urgente quanto mais complexo. Mesmo porque o Decreto $n$ ? $67.326 / 70$ criou condições favoráveis ao aperfeiçoamento da administração de pessoal em nosso País e, ao mesmo tempo, uma situação de "fato consumado" que urge aprimorar.

\section{Objetivo-Síntese}

Na medida em que funcionar eficientemente será o Sistema de Pessoal Civil da Administração Federal (SIPEC) um poderoso instrumento no arsenal dos mecanismos disponiveis, para obtenção daquele "Objetivo-Síntese" colimado e definido nas "Metas e Bases para a Ação de Govêrno": "I) Ingresso do Brasil no mundo desenvolvido, até o final do século. Conforme já se esclareceu, construir-se-á, no País, uma sociedade efetivamente desenvolvida, democrática e soberana, assegurando-se, assim, a viabilidade econômica, social e política do Brasil como grande potência". (Documento divulgado em setembro de 1970, pág. 15.)

A fôrça de trabalho representada pelos contingentes de servidores públicos, incorporada à massa dos demais trabalhadores, tem um papel decisivo a desempenhar como uma das componentes estratégicas, cujos coeficientes de produtividade poderão ser multiplicados através de uma política de pessoal inteligente, dinâmica e humana, à altura daquele grande objetivo nacional. Que é exatamente o que os brasileiros esperam do govêrno e do funcionalismo, cuja missão foi recentemente caracterizada pelo Chefe da Nação com realismo e clareza: ... "todos os dias, ao longo de um ano já de exercício da presidência, tenho presente o papel do funcionalismo público. como verdadeiro sistema circulatório da ação governamental" "... e volto-me, neste grande dia, para o funcionalismo público de meu País onde vejo o instrumento de trabalho - que espero sempre mais prestante - e o contingente humano que desejo cada vez mais motivado, participante e feliz." 


\section{Patrimônio do Servidor}

Pouco depois dêsse pronunciamento o Presidente Garrastazu Médici deu uma demonstração de alto aprêço pelos servidores públicos ao assinar, durante a reunião ministerial de 30-10-70 (primeiro aniversário de seu govêrno), Mensagem ao Congresso Nacional propondo a aprovação de Lei Complementar que institui o Programa de Formação do Patrimônio do Servidor Público, Civil e Militar. O processo de formação do patrimônio é semelhante à mecânica do Fundo de Participação Social recentemente aprovado pelo Congresso Nacional, prevendo correção monetária e juros de $3 \%$ ao ano em cadernetas individuais a serem expedidas pelo Banco do Brasil. A União, os Estados, os Municípios, o Distrito Federal, os Territórios, as autarquias, emprêsas públicas, sociedades de economia mista e fundações contribuirão para o referido Programa mediante recolhimento mensal ao Banco do Brasil das parcelas discriminadas no texto da Lei Complementar.

\section{Ação Administrativa}

No quadro das "Metas e Bases para a Ação de Govêrno" (doc. citado, 9-70, pág. 10) a problemática administrativa através da qual o Estado planeja, vive e atua, foi elevada à categoria de uma das 12 conquistas essenciais a serem alcançadas por meio de medidas e instrumentos cuja definição concreta constitui a finalidade principal das mencionadas "Metas e Bases".

O reconhecimento da natureza prioritária daquela problemática é acontecimento auspicioso como demonstração de uma nova mentalidade. A ação administrativa do Poder Executivo, integrada no contexto de uma estratégia mais ampla convergirá para a execução de uma política que o planejamento governamental resumiu em poucas palavras: "... II - Criação de condições para o funcionamento de setor público moderno e eficiente, revertendo-se a tendência, observada antes de 1964, para a deterioração dos serviços, a expansão desmedida de atribuições e do número dos servidores e o crescente desequilibrio financeiro das entidades de administração indireta.

Para consolidar os resultados já alcançados pelos dois primeiros governos da Revolução, manter-se-á, no serviço público direto e autárquico - para estabelecimento de administraÇão eficiente e motivado, uma política de austera contenção de dispêndios burocráticos administrativos; de gradual redufão, em certos órgãos, de pessoal excedente; de criação de sistema de assessoramento de alto nível para os órgãos de 
decisão; de revalorização do sistema do mérito; de consolidação progressiva da carreira de funcionário em tempo integral; de treinamento intensivo nas áreas prioritárias, para atualização de conhecimentos e incorporação de novos métodos de trabaIho; de equipamento adequado dos principais órgãos de decisão e execução. Nas emprêsas governamentais, modernizarse-á a administração, estabelecendo-se sistemas de contrôles de custos e, bem assim, diretorias técnicas relativamente estáveis, com o propósito de fazê-las funcionar tão eficientemente como as do setor privado". (Doc. citado, pág. 10).

\section{II - TEMÁTICA DOS SISTEMAS}

\section{Substância}

A prodigiosa fôrça semântica do vocábulo "sistema" contribuiu para incorporá-lo ao patrimônio científico, técnico e cultural da humanidade. À semelhança de inúmeros outros conceitos de utilização universal em todos os domínios do conhecimento, "sistema" tem as suas remotas origens no mundo surpreendente da filosofia grega.

A análise etimológica evidencia as virtualidades do poderoso conceito ao qual se acham estreitamente vinculadas as idéias de ordem, organização, conjunto, combinação, agrupamento, reunião, arranjo, plano, método, esquema, entrelaçamento, regularidade, sinergia. Em suma, a noção ontológica de um complexo orgânicamente constituído, cujas partes componentes se entrosam numa tessitura de relações de analogia, cooperação, dependência recíproca e finalidade específica.

A natureza eminentemente dinâmica e teleológica do conceito de "sistema" possibilitou o seu aproveitamento na órbita da filosofia, da metafísica, da lógica, das matemáticas, de onde foi se irradiando para as ciências naturais e sociais, generalizando-se o seu emprêgo com o avanço científico e tecnológico, em plena fase de expansão incontrolável decorrente do advento da eletrônica, da cibernética e da implantação dos sistemas informáticos.

Sendo o próprio universo um macro-sistema de dimensões infinitas coube à filosofia a tentativa pioneira de compreendêlo e desbravá-lo pela observação dos fenômenos da natureza e da vida.

Surgiu, destarte, o conhecimento dos "sistemas" de existência natural objetivamente comprovada, ou seja, o imenso aglomerado de elementos, estruturas, entidades ou sêres interrelacionados num emaranhado de princípios, fôrças e relações 
de afinidade e coordenação. É neste sentido de conjunto de normas, fatos e realidades condicionadas, solidárias e interrelacionadas, que o conceito de "sistema" tem seu maior campo de aplicação, o que ocorre, por assim dizer, na área de tôdas as ciências.

\section{Variedade e complexidade}

As enciclopédias e dicionários enumeram e definem uma variedade impressionante de "sistemas" objetivos - os galáxicos e planetários, o solar, o atômico, o nervoso, o endócrino, o circulatório, o digestivo, o reprodutivo, os geológicos e assim sucessivamente, no âmbito da astronomia, da física, da biologia, da fisiologia, da geologia, da mineralogia, da química e da totalidade das ciências da natureza e do homem.

Mas, igualmente importantes são os "sistemas" oriundos da capacidade criadora humana, de concepção arbitrária e subjetiva, verdadeiras emanações ou projeções do homem sôbre o mundo em que vive e que se destinam a dominá-lo, discipliná-lo ou afeiçoá-lo às suas dimensões e necessidades.

O homem pensa e age em função das instruções ou comandos que recebe de um cérebro cujo funcionamento obedece a insondáveis, profundos e inexoráveis impulsos de organização e sistematização. Nada mais lógico, por conseguinte, do que a criação humana de "sistemas" conceituais com objetivos eminentemente teóricos ou pragmáticos, por analogia com os sistemas naturais físicos, orgânicos ou mecânicos.

Aos "sistemas" - naturais ou analógicos - se opõem os conceitos negativos de caos, desordem, confusão, incoerência.

\section{Semântica}

André Lalande, no clássico "Vocabulaire Technique et Critique de la Philosophie", logrou resumir o conceito de "sistema" como um ... conjunto de elementos materiais ou não, reciprocamente dependentes uns dos outros de maneira a formar um todo organizado... (1962, "Presses Universitaires de France", 9ème edition, pág. 1.096).

Para Walter Brugger, os "sistemas" são uma exigência da razão que em tôda pluralidade busca a unidade e a ordem; os "sistemas" nascem por conexão e são ordenados por um princípio comum graças ao qual cada parte tem, no conjunto, o seu lugar e a sua função... Conhecimentos isolados ou desconexos não podem constituir um "sistema". .. que pressupõe articulação e uma idéia de totalidade (Dicionário de Filosofia, 
Philosophisches Worterbuch, 1953, trad. Editorial Herder, página 360$)$.

O conceito de "sistema" aplica-se simultâneamente aos agregados naturais e artificiais ou imateriais; as respectivas unidades componentes se movimentam, funcionam ou operam, em todos os casos, sinèrgicamente, em obediência a alguma forma de contrôle imanente, ou de acôrdo com um princípio normativo indispensável à coesão e coerência do conjunto. (System: combination of parts in a whole; orderly arrangement according to some common law; collection of rules and principles; connected body of principles in science or art; method of transacting business... Sistematology: the doctrine of systems... (Webster's New Standard Dictionary, The Webster's Encyclopedic Dictionary, 1969).

A conceituação transcrita no Brockhaus assemelha-se à norte-americana: conhecimentos experimentais interdependentes do ponto de vista histórico e racional; estrutura; corpo de doutrina: sistema Hegeliano. 2) Plano, ordenação: sistema de administração; sistema parlamentar; dar sistema a alguma coisa. (Das System - zusammenhaengende Erfahrungserkenntnis nach einen vernunftgemaessen Gesictspunkt; Gliederbau, Lehrgebaeude: das Hegelsche System. 2) Plan, Ordnung: das Siystem der Verwaltung; das parlamentarische System; System in etwas bringen. Der Sprach - Brockhaus, p. 677 - Deutsches Bildwoerterbuch fuer jedermann. Sechste, verbesserte Auflage. Eberhard Brockhaus. Wiesbaden, 1953).

Os lexicógrafos mais conhecidos - Larousse, Brockhaus, Morais, C. de Figueiredo, Caldas Aulete, B. de Holanda, Antenor Nascentes, entre muitos - sintetizam e, por assim dizer, desidratam a semântica dos "sistemas" em breves linhas, com ligeiras variações: ... conjunto de partes coordenadas entre si; corpo de doutrina; combinação de partes convergindo ou concorrendo para um certo resultado; aglomerado de leis ou princípios que regulam determinada ordem de fenômenos; reunião de meios ou processos empregados para alcançar um fim qualquer; plano, método, hábito, uso; forma de govêrno ou constituição política ou social de um Estado...

Sintéticos no enunciado e conceituação dos "sistemas", aquêles autorizados dicionaristas porfiam, todavia, na enumeração de uma infinidade de exemplos concretos que vão desde as galáxias aos sistemas métrico-decimal e ortográfico.

Poder-se-ia observar que a própria desordem seria passivel de institucionalização como ocorreu durante muito tempo com 
o famigerado "Spoils System". Mas, em 1883, a Civil Service Commission acabou com o caos e implantou a ordem - o "Merit System".

\section{Reformulação e aplicabilidade}

Evidentemente, no quadro atual dos conhecimentos humanos, a explosão científica e tecnológica vem consolidando a ótica ou enfoque interdisciplinar e multidimensional dos problemas: tanto no concernente à pesquisa, como no tratamento e formulação das soluções possíveis.

Em conseqüência, quaisquer tentativas de classificação e nomenclatura correm o perigo de uma rápida obsolescência, mas se apresentam, contudo, válidas, pelo sentido didático ou pedagógico de que se revestem.

O que importa assinalar no referente à sistematologia não é, contudo, o grande número, as características, complexidade e funcionalidade dos "sistemas" - tanto no tocante aos originários, ou de 1 o grau - como no que se refere aos derivados, analógicos, artificiais, provenientes de uma elaboração intelectual do homem.

O essencial é acentuar a vulnerabilidade, mutabilidade e transitoriedade desta última categoria, a dos "sistemas" humanos, ou de 2 ? grau.

Na esfera das ciências sociais a utilização dos "sistemas" adquiriu proporções de legítima obsessão como instrumento de pesquisa e ferramenta de trabalho. Destarte, as ciências administrativas em geral e, muito especialmente, a administração pública, foram compelidas à elaboração de modelos próprios, adequados à sua problemática.

\section{Modelos}

Exatamente no campo das ciências administrativas é que a noção de "sistemas" se tem caracterizado pela sua extrema fecundidade, ensejando múltiplas aplicações teóricas e práticas, muitas das quais imprevistas, sofisticadas e quiçá insólitas.

O fato deve ser encarado com naturalidade, embora ocorra com maior dificuldade e menos freqüência nos países periféricos do mundo subdesenvolvido, cujas instituições geralmente transplantadas de outros povos - constituem um reflexo de civilizações alienígenas.

Encerrado o processo colonial, a emancipação daqueles países, sendo històricamente um fato recente, não permitiu, pela exigüidade do tempo decorrido, a elaboração de modelos 
autóctones, concepções e estilos nacionais independentes na organização dos serviços públicos.

Poder-se-ia afirmar que estão condenados à importação do know-how, ao consumo da tecnologia "enlatada", até o dia em que os respectivos sistemas universitários de pesquisa e ensino, no campo educacional, científico e tecnológico, resolvam o problema crucial do pessoal qualificado, sem o qual os planos, os programas e as técnicas permanecerão no papel, e o próprio desenvolvimento carecerá de sentido pela falta de condições mínimas de exeqüibilidade.

Na maioria dêsses países, o exasperante primado da casuística e da "paperasserie", a hipertrofia dos rituais burocráticos, a mentalidade cartorial dos "contrôles" redundantes e o artesanato bacharelesco dos pareceristas, favorecem a instalação de feudos ou redutos de obscurantismo que reagem contra as inovações modernizantes e lutam pela manutenção dos privilégios e dos interêsses arraigados.

\section{A exceção brasileira}

Algumas notáveis exceções se podem citar relativas aos países que queimaram etapas, exatamente aquelas nações que já ultrapassaram a barreira da arrancada, o difícil take-off rostowiano, como, felizmente, é o caso do Brasil, que marcha, em ritmo acelerado, no roteiro de um processo irreversivel de desenvolvimento integrado e auto-sustentado.

\section{Integração administrativa}

$\mathrm{Na}$ maioria dos países, desenvolvidos ou periféricos, observa-se a aceleração do processo evolutivo no sentido de uma melhor integração administrativa como resultado da utilização dos "sistemas": não há mais lugar para órgãos ou serviços amontoados, desarticulados e conflitantes na disputa de recursos humanos, financeiros e materiais, universalmente escassos.

A noção generalizada de "sistemas" administrativos, tanto do ponto de vista técnico como no referente à aplicabilidade do conceito, é pràticamente a mesma, em tôda a parte. Wilburg Jiménez Castro escreveu sôbre o assunto: Por "sistema se conpreende el conjunto de órganos, principios e normas sobre una materia, enlazados o coordinados entre sí, tan estrechamente, que constituyen un todo indivisible, a pesar de la relativa independencia funcional u operativa que pueden tener sus partes componentes. Esas partes actuan com una misma orientación y satisfacen un objetivo común. El sistema es así un todo organizado y articulado, no acumulado, cuyo crecimiento va de 
adentro hacia afuera haciendo a cada una de sus partes más fuerte y adecuada a sus finalidades individuales y coletivas, sin alterar la proporción que cada una de ellas tiene del conjunto" (in "Sistemas Prioritarios para la administración del desarrolo", documento preparado pelo Lec. Wilburg Jiménez Castro, Técnico das Nações Unidas, para o Seminário sôbre Aspectos Administrativos da Execução de Planos para o Desenvolvimento realizado em Santiago, Chile, 1968. O autor é ex-Diretor do ICAP - Instituto Centro Americano de Administração Pública.)

\section{Nova Mentalidade}

O que se busca através de reformas generalizadas em todos os setores, é o modêlo dos conjuntos organizados, cuja problemática se procura resolver em têrmos de planificação estratégica, administração coordenada e eficácia operativa controlada, ou seja, a implantação de novas técnicas de administração através de sistemas, objetivos e resultados.

Ao invés da tradicional predominância dos conceitos meramente jurídicos, pretende-se uma nova mentalidade que se poderia simbolizar na "costmindedness" a que se refere MacNamara.

Conforme acentuou o Prof. Calimeri, em um dos seus magníficos ensaios: ... "A eficácia e a eficiência do funcionamento dos sistemas, dependem, cada vez mais, do modo como são tomadas as decisões. Naqueles mais avançados, observa-se a tendência a passar das formas de decisão tradicionais (baseadas no hábito, na routine decisória, em estruturas organizativas específicas, na experiência, no parecer, na instrução) a formas baseadas em técnicas avançadas (pesquisa operacional, análise matemática, uso dos modelos, simulação, elaboração eletrônica dos dados, técnicas heurísticas). Ansoff distingue, no funcionamento do sistema-emprêsa, três tipos de decisão: de ordem estratégica, de ordem administrativa e de ordem operacional". ... ("L'efficacia e l'efficienza del funcionamento dei sistemi dipendono, sempre più, dal modo come vengono prese le decisioni. In quelle più progrediti si osserva la tendanza a passare dalle forme di decisioni tradizionali (basate sull'abitudine, sulla routine decisionale, su particolari strutture organizzative, sull'esperienza, sull'giudicio, sull'instruzione) a forme basate su tecniche progredite (ricerca operativa, analisi matematica, uso dei modelli, simulazione, elaborazione elettronica dei dati, tecniche euristiche). Ansoff differenzia, nel funzionamento del sistema-azienta, tre classe di decisioni: di ordine strategico, di ordine amministrativo e di ordine operativo". - (M. Calimeri, in 
la Riforma della Pubblica Amministrazione vista come Evoluzione del Sistema, La Scienza e la Tecnica della Organizzazione nella Pubblica Amministrazione, 1969, Gennaio-Marzo, p. 20).

\section{Sistema Integrado de Planejamento, Programação e Orçamento}

Acontecimento decisivo na evolução dos sistemas administrativos foi a introdução do "Planning, programming, budgeting System" (P.P.B.S.) pelo govêrno norte-americano a partir de 1960 , com a nomeação de MacNamara para Ministro da Defesa. Ocorreu então uma radical e profunda transformação no concernente à conceituação, métodos, técnicas e estilos de administração de tal forma que se costuma caracterizar como decisiva e genial a contribuição de MacNamara no campo das ciências administrativas. Dêle se afirma que "depois de haver transformado a indústria automobilística, reformou a administração norte-americana." apud J. J. Servan Schreiber no "bestseller" O Desafio Americano).

Não cabe, no limite preestabelecido dêstes breves comentários, uma análise desenvolvida do "Planning, Programming, Budgeting System", que os leitores possivelmente interessados encontrarão na vasta bibliografia especializada a respeito existente. Devo, porém, chamar a atenção para o fato de que o Sistema Integrado de Planejamento, Programação e Orçamento tem sido objeto de sérios estudos nas principais Universidades e está sendo introduzido na administração dos países mais desenvolvidos com as adaptações exigidas pela peculiaridade das condições nacionais, grau de desenvolvimento atingido, nível cultural e demais fatôres que singularizam cada situação. Os objetivos colimados são, substancialmente, a obtenção de elevados índices de eficiência, a escolha de alternativas ótimas na solução de cada problema, a crescente utilização das técnicas de quantificação, determinação dos custos e avaliação do desempenho. Através do emprêgo de uma metodologia altamente eficaz, em que se destacam a "análise dos sistemas", as técnicas e pesquisas sôbre as relações "cost-utility", "cost-benefits", "cost-effectiveness" e "sensitivity-analysis", opera-se, efetivamente, uma radical transformação da mentalidade dos agentes, a par de resultados substancialmente melhores. São critérios novos que permitem acelerar o ritmo de funcionamento de qualquer organização e estabelecimento de padrões qualitativos e quantitativos que possibilitam a avaliação do desempenho do sistema como um todo organizado e de cada uma das suas partes componentes. 
(Para quem desejar informações mais pormenorizadas, será de grande utilidade consultar: 1) E. S. Quade, Tecniques d'analyses de sistèmes pour le P.P.B.S. Rand Corporation, mars, 1966 - trad. francesa; 2) R. N. Anthony, Sistemi di pianificazione e controllo: schema di analysi, Ed. E. Kompass; 3) H. A. Simon, The New Science of Management Decision, in "The Shape of Automation", Ed. Harper and Row, 1965; 4) N. S. M., A Modern Design for Defense Decision - A McNamara-Hitch-Enthoven Anthology, Ed. Ind. Coll. A.F., Industrial College of the Armed Forces, Washington; 5) E.S. Quade, Systems Analysis: Techniques for Planning-Programming-Budgeting. The Rand Corporation, 1966). A metodologia proveniente do Sistema integrado de Planejamento, Programação e Orçamento (P.P.B.S.) aplica-se, com as adaptações que se fizerem indispensáveis, aos demais sistemas prioritários da administração: planejamento, orçamento, modernização administrativa, pessoal, estatística, contabilidade pública, compras, abastecimento e armazenamento (material), ou sempre que se tornarem imperativas as exigências de coordenação centralizada, funcionalidade e eficiência global.

\section{III - EXPERIENCIA BRASILEIRA}

\section{Sistemas embrionários}

Paradoxalmente, no caso brasileiro, o aparecimento dos "sistemas" resultou menos da praxis universitária e da atuação dos intelectuais do que da iniciativa governamental, no bôjo de textos legais de precária exeqüibilidade.

As origens da implantação de "sistemas" modernos no contexto da administração brasileira remontam à Lei $n$ \% 284 , de 1936, que criou o Conselho Federal do Serviço Público Civil e, em cada Ministério, uma Comissão de Eficiência incumbida de "estudar permanentemente a organização dos serviços afetos ao respectivo Ministério, a fim de identificar as causas que Ihes diminuem o rendimento" e "propor as modificações necessárias à racionalização progressiva dos serviços".

Ao referido Conselho sucedeu o DASP criado pela Constituição de 1937, e organizado pelo Decreto-lei no 579 , de 30-7-38. Englobando as atividades de orçamento e organização, pessoal, material, edifícios públicos e documentação, o DASP surgiu como uma expressão hipertrofiada das doutrinas de administração de Willoughby e Leonard White, transplantadas para o nosso País. O seu aparecimento no cenário da Administração Pública marcou o apogeu das teorias dos "departamentos de administração geral". 
Enquanto teve o respaldo do prestígio que the proporcionava o Presidente Vargas, prestou imensos serviços ao povo brasileiro e foi, incontestàvelmente, um fator de modernização, com iniciativas pioneiras e arrojadas no concernente à racionalização administrativa. Mas, com a queda do Presidente Vargas, em 1945, sobreveio uma das muitas reformas que pontilharam de vicissitudes a existência da discutida Instituição: O Decretolei $n$ ? 3.323-A, extinguiu a Divisão de Organização e Coordenação e a Divisão de Orçamento, criando, em substituição, a Divisão de Orçamento e Organização, além de outras mutilações perpetradas na vigência de um govêrno provisório de três meses.

O fato é que, embora invocando pretextos de economia e maior coesão entre os processos de organização e elaboração orçamentária, a fusão daquelas duas Divisões teve como resultado exclusivo, a liquidação do "sistema" embrionário de Organização e Métodos que deveria ter sido cuidadosamente preservado.

O chamado "Sistema" de Material, bem delineado no papel, desintegrou-se ao contacto com a realidade quotidiana e não resistiu ao "teste" da aplicabilidade prática.

De concepção grandiloqüente, abrangendo, de início, 6 campos diferentes de atividades e uma pletora de órgãos componentes, o "Sistema" de Material, não obstante, desbravou o caminho numa das áreas mais complexas - verdadeira zona de sombra da administração. Prestou assinalados serviços. Mas, à semelhança dos demais "sistemas" ensaiados não resistiu ao "golpe" de 1945. Foi também mutilado e sofreu um colapso: são notórias as lamentáveis conseqüências do episódio, dispensando comentários adicionais.

No tocante ao "Sistema" de Pessoal o malôgro foi completo não havendo sido sequer delineado um projeto dotado de viabilidade conceitual, técnica e operacional. Ao contrário, ocorreu uma regressão à estaca zero do empirismo absoluto, acelerando-se, por outro lado, numa perspectiva catastrófica, - ritmo de deterioração da entidade e dos serviços públicos, em geral, sòmente jugulada com o advento do Decreto-lei n? $200 / 67$.

Nesse rápido e incompleto bosquejo percebe-se a marcha lenta das tentativas frustradas, a procissão sombria de sucessivos fracassos. 


\section{Sistemas de Contrôle}

Quanto à implantação dos Sistemas de Administração Financeira, Contabilidade e Auditoria, sòmente depois do Decreto-lei $n$ ? 200/67, logrou o Poder Executivo situar-se na terra firme dos fatos, apesar da inflação de leis e normas que, de há muito, perturbam a ação administrativa do Estado nessa imensa e complexa área especializada. Trata-se de matéria que demanda uma análise especial porque dela depende, notadamente da ótica dos Orçamentos públicos, a própria viabilidade de uma política de pessoal dotada de coeficientes de racionalidade, exeqüibilidade e objetividade. A problemática dos aludidos sistemas, no que se relacionam com a administração de pessoal será objeto de um artigo posterior.

Enquanto se promove em todos os setores e níveis da Administração Federal a implantação dos citados Sistemas, com avanços e retrocessos nos planos da doutrina e da experiência factual, convém refletir acêrca das conclusões que, a respeito dos sistemas de contrôle no quadro da Reforma Administrativa, chegaram dois eminentes economistas do Ministério da Agricultura: ". . . O importante nesta fase é o estabelecimento de princípios de análise sôbre a administração em geral, principalmente a financeira, o que facultará valiosos subsídios para a elaboração de uma estratégia de ação integrada para a correção dos vícios e erros, com a aplicação de medidas punitivas nos casos comprovadamente dolosos, cumprindo-se, por etapas, as necessárias reformulações de atitudes e hábitos, a fim de forjar uma mentalidade consciente e atuante no Serviço Público. Pois em sua ausência, muito mais do que simples modificações de estruturas formais, organogramas e fluxogramas, a Reforma Administrativa importa em uma reformulação de mentalidade, de pontos-de-vista e de modos de ser". (Reinhold Stephanes e Norival O. Kwiatkowsvi, Economistas, I.G.F. do Ministério da Agricultura in A Reforma Administrativa e os Sistemas de Contrôle, R.S.P., vol. 105, nọ 1/70).

\section{A Coordenação Central do Decreto n? 200/67}

Assim como a revolução de 1930 possibilitou o advento da Lei n? 284/36, da mesma forma a revolução de 1964 criou, com o Decreto-lei n? 200/67, condições favoráveis à implantação da Reforma Administrativa - aspiração permanente do povo brasileiro, preocupação absorvente das elites universitárias e do govêrno - mas sempre postergada como empreendimento visionário. O Decreto-lei no 200/67 constituiu, sem sombra de dúvida, um impacto, pela relevância do conteúdo, 
alcance e repercussões das providências decorrentes de sua progressiva aplicação.

Não importa o fato de conter várias incorreções, nem a timidez de algumas das suas recomendações; nem, mesmo, a ocorrência de sérias e imperdoáveis omissões: basta dizer que não contém uma só palavra acêrca dos sistemas informáticos.

O que se deve proclamar, acima de tudo, é o sentido histórico de que se reveste como acontecimento decisivo na trajetória da Administração Pública. Não sòmente ensejou a viabilidade de uma reforma - até então relegada à condição de mito ou elefante branco, em virtude das tentativas malogradas que a antecederam - como vem acarretando uma avalancha de conseqüências práticas, medidas concretas e profundas repercussões: exemplo convincente é, precisamente, a implantação dos "Sistemas" prioritários da administração no contexto de um país em fase de desenvolvimento acelerado e auto-sustentado.

O Decreto-lei no $200 / 67$, se não logrou introduzir muitas e radicais inovações, situando-se nos parâmetros das recomendações cautelosas, conseguiu, no entanto, dinamitar estruturas carcomidas e acelerar o ritmo da máquina governamental e administrativa, despertando-a para os avanços científicos $e$ tecnológicos que, mais cedo do que se presume, modelarão a fisionomia de uma nova administração adequada às dimensões, condições e perspectivas da Nação Brasileira.

É possível, desde já, marchar gradualmente para uma administração germinada pelo complexo triangular GovêrnoUniversidade-Emprêsa, despojada do formalismo superficial, escoimada do sadismo dos contrôles irracionais, liberta da mentalidade notarial dos pareceristas e da alienação burocrática - em suma, uma administração vacinada contra as sobrevivências de uma sociedade tradicionalista pré-industrial.

As contribuições mais relevantes no elenco das providênciàs do Decreto-lei no 200/67 serão, talvez, as consubstanciadas nos arts. $30,94,115$ e 121.

Evidentemente, a filosofia, os princípios gerais (planejamento, coordenação, descentralização, delegação de competência e contrôle), a organização da Administração Federal e as diretrizes para a reforma são pressupostos fundamentais.

\section{Providências básicas}

Todavia são as medidas e repercussões decorrentes dos mencionados artigos que asseguram a exeqüibilidade da Reforma Administrativa e a obtenção das metas a serem progressi- 
vamente atingidas. Nelas encontra-se o "core", o núcleo vital, o elenco das providências básicas, a fonte de onde promanará a energia vitalizadora do conjunto:

1) - Organização, sob a forma de sistema, das atividades de pessoal, orçamento, estatística, administração financeira, contabilidade e auditoria, serviços gerais, além de outras atividades que, a critério do Poder Executivo, necessitem de coordenação central. (art. 30).

2) - Estabelecimento de uma autêntica política de pessoal sintonizada com as exigências do desenvolvimento nacional, as conquistas científicas e tecnológicas, as aspirações do funcionalismo e aquelas conveniências da Administração Federal que atendam, simultâneamente, aos imperativos da modernização e da justiça social (art. 94).

3) - A instituição do DASP como órgão central do sistema responsável pelo estudo, formulação de diretrizes, orientação, coordenação, supervisão e contrôle dos assuntos concernentes à administração do pessoal civil da União (art. 115).

4) - Dimensionamento e implantação pelo Centro de Aperfeiçoamento de um esquema de assessoramento superior da Administração Civil através de medidas relacionadas com o recrutamento, seleção, aperfeiçoamento e administração daquele assessoramento (art. 121).

\section{Ressurgimento e maturidade}

O ressurgimento dos "sistemas" em condições de viabilidade operativa no campo da Administração, depois dos malogrados ensaios tentados pelo DASP com relação às atividades de pessoal, organização e métodos, material e orçamento é, antes de mais nada, uma tardia demonstração de maturidade.

Um esfôrço válido de atualização tecnológica, no sentido de captar as potencialidades de um conceito extremamente fecundo. Uma coisa, porém, é a intenção contida nas recomendações do Decreto-lei n? 200/67; outra, ainda mais difícil, será traduzi-las em têrmos de ação concreta, atos positivos, medidas práticas.

O conceito de "sistema" em si é uma abstração, um imponderável: mas as possibilidades que nêle se contém são, por analogia, como a energia intra-atômica, cuja captação pode efetuar-se tanto no sentido explosivo e destruidor das bombas, como, de preferência, no roteiro positivo do aproveitamento da energia para finalidades pacíficas geradoras de riqueza. 


\section{Panorama do SIPEC}

A reformulação do próprio DASP, através do Decreto $n$ ? $66.222 / 70$ foi, incontestàvelmente, uma preliminar importante no sentido da organização do Sistema de Pessoal Civil da Administração Federal (SIPEC).

O desempenho de sua missão prioritária como órgão Central do Sistema seria inviável sem as medidas de reorganização levadas a efeito e o início de um processo de aparelhamento humano, equipamento técnico e recuperação do prestígio da instituição, - problema que a "Revista do Serviço Público" já teve oportunidade de abordar (cf. Editoriais dos n? 1 e 2, Vol. 105).

Preparado o terreno, tornou-se inevitável o Decreto $n$ ? 67.326 , de 5 de outubro de 1970 , que traçou os delineamentos, deu conteúdo objetivo e expressão aos dispositivos do Decretolei $n$ ? 200/67, e organizou, sob a forma de sistema, as atividades de administração de pessoal do serviço civil do Poder -Executivo.

Integrado pelas unidades organizacionais que, na Administração Direta ou nas Autarquias, exerçam atividades específicas de pessoal - tem o SIPEC uma estrutura na qual se entrosam:

1 - O DASP, como Órgão Central.

2 - órgãos Setoriais: Departamentos, Divisões ou outras unidades específicas de pessoal civil dos Ministérios e dos órgãos da Presidência da República, de maior hierarquia na respectiva área administrativa.

3 - órgãos Seccionais: Departamentos, Divisõês ou outras unidades específicas de pessoal das Autarquias.

4 - 0 Conselho Federal de Administração de Pessoal e a Comissão de Coordenação do Sistema de Pessoal.

Atendidas as peculiaridades dos serviços poderão ser criadas "Unidades Regionais" e, em cada Órgão integrante do Sistema, Unidades de Pesquisa, de Orientação, Coordenação e Contrôle, e de Execução. Para realização dos encargos especializados, quando necessário, está prevista a criação de Grupos-Tarefa de duração temporária.

Essa, em resumo, a composição do SIPEC. Para os fins do Decreto no $67.326 / 70$, as funções básicas da administração de pessoal correspondem às desenvolvidas pelas cinco Coordenações do DASP: Classificação e Retribuição de Cargos 
e Empregos; Recrutamento e Seleção; Cadastro e Lotação; Aperfeiçoamento e Legislação de Pessoal. O SIPEC funcionará dentro de parâmetros preestabelecidos e atuará no limite das fronteiras acima delineadas. A magnitude do empreendimento avulta como empolgante desafio à capacidade realizadora dos diretores, chefes e assessôres de pessoal. Por isso mesmo justifica-se uma ligeira análise do conteúdo do Decreto no $67.326 / 70$, com a finalidade exclusiva de detectar as vulnerabilidades do Sistema e contribuir para o seu aperfeiçoamento. Não se trata de "crítica", mas de um necessário exercício de "inconformismo construtivo" a fim de que não se repita o malôgro das anteriores tentativas de implantação de um Sistema de Pessoal.

\section{Ligeira Análise}

De início, cabe observar que o Decreto n? 66.326/70, chegou quase um ano depois do encerramento das reuniões de de diretores de pessoal promovidas pelo DASP em 1969. Apesar da demorada elaboração do texto - as providências nêle consubstanciadas não equacionam com realismo a problemática de uma administração de pessoal sintonizada com a estratégia de desenvolvimento nacional.

Ao lado de injustificáveis omissões ocorrem redundâncias e postulações imprecisas que "hurlent de se trouver ensemble". Assim, a organização do Sistema definida no § único do art. $10^{\circ}$ como o conjunto integrado de "tôdas as unidades organizacionais de qualquer grau incumbidas especificamente das atividades de administração de pessoal da Administração Direta e das Autarquias" é desnecessàriamente objeto de outros dispositivos como os contidos no art. $5^{\circ}, \S 33^{\circ}$, e no $\S 1$ ? do art. $3^{\circ}$, III.

Quanto ao elenco das funções básicas de administração de pessoal a enumeração transcrita no art. 2 ?, além de incompleta, dá a impressão de uma vinculação teleológica do Sistema à atual estrutura do DASP. Ora, o funcionamento de qualquer instituição sofre o impacto de freqüentes modificações fato, de resto natural, porque a administração é um fenômeno dinâmico que não se pode emparedar no limite dos organogramas. Daí a inconveniência de "amarrar" o Sistema a uma determinada estrutura.

A tentativa de fazer coincidir as aludidas funções com as 5 Coordenações do DASP: COCLARCE, CODERSEL, CODASLO, CODAPER e COLEPE, carece de imaginação criadora. Nos têrrmos do art. 4? , parágrafo único, pretende-se estender aos Órgãos Setoriais e Seccionais, com evidente intuito de padronização, a estrutura das aludidas coordenações às Unidades 
de Planejamento, Coordenação, Contrôle e Execução, bem como aos Grupos-Tarefa, permitindo-se, porém, em caráter excepcional, que mantenham Unidades de Pesquisa. Esta restrição, no tocante à pesquisa e planejamento, reduzirá a capacidade decisória dos órgãos Setoriais e Seccionais. Os artigos 4 ? e 7 , aliás, não se encontram devidamente ajustados.

A experiência demonstra que os órgãos de planejamento regional como a SUDENE e a SUDAM, e o complexo do INPS - para citar apenas três exemplos - têm de estruturar a organização administrativa de pessoal em função da especificidade técnica dos seus objetivos, das suas peculiaridades de funcionamento, dimensões e conveniências.

É uma temeridade exagerar a padronização das estruturas em nome das supostas vantagens de uma uniformidade desmentida pelas realidades quotidianas ou para que os organogramas do Sistema se apresentem com a elegante sofisticação de uma simetria impossivel.

Cada órgão deverá ter a organização mais adequada aos imperativos de sua missão prioritária, necessidades operativas e exigências institucionais.

Ainda no tocante à composição do SIPEC, deverá integrálo o Conselho Federal de Administração de Pessoal, cujas atribuições serão fixadas em Regimento aprovado pelo DiretorGeral do DASP. Vários especialistas questionam a indispensabilidade dêsse órgão que, inserido na complexa estrutura do SIPEC se limitaria, pràticamente, a reproduzir as atividades jurídico-normativas das Consultorias Jurídicas e da própria Consultoria-Geral da República (Decreto-lei no 200/67, arts. 118 e 119). Alguns teriam preferido o Contencioso Administrativo ou, quiçá, um Tribunal Administrativo especializado. A questão foi porém transferida para outra oportunidade. Na verdade, não existe nenhuma instância melhor de consulta e colaboração, nos assuntos de administração de pessoal, do que a própria constelação dos órgãos integrantes do SIPEC.

Quanto à Comissão de Coordenação de Pessoal (art. 9 ${ }^{\circ} e$ $\S \S)$ complicou-se a sua composição e funcionamento. Curiosamente foram excluídos os dirigentes dos órgãos seccionais, mas $0 \S 2$. do mencionado artigo 9 \% abriu as portas à participação de todo mundo: quaisquer funcionários poderão ser convocados desde que contribuam para melhor apreciação dos assuntos em pauta.

A manutenção de representantes permanentes ou temporários do DASP junto aos órgãos Setoriais ou Seccionais é 
outra interessante iniciativa: serão os "plenipotenciários" do Órgão Central. Há pessimistas que reputam perigosa essa inovação: algo como um atalho para exacerbação fiscalizadora e enrijecimento dos "contrôles". Alguns alegam que reuniões periódicas acopladas a uma simples rêde de "telex" interligando a totalidade dos órgãos do Sistema seria medida mais eficiente, mais prática e menos onerosa do que uma equipe de intermediários.

Quanto ao provimento dos cargos ou funções de dirigentes, assinale-se que o problema abrange a generalidade das chefias do Serviço Público, ultrapassando as fronteiras dos órgãos de pessoal. Até agora o estabelecimento de pré-condições de qualificação para o eficiente exercício dos cargos de direção tem encontrado barreiras intransponíveis. 0 dispositivo incluído no texto tem o sabor de um exercício acadêmico, de uma digressão amena no campo das doutrinas de administração de pessoal. Convém insistir no fato de que postergar a solução do problema das chefias qualificadas é transformar qualquer tentativa de reforma em uma mitologia e reduzir o "Sistema do Mérito" a uma impostura. As origens das queixas e acusações assacadas contra a Administração Pública se encontram nessa diátese da falta de credibilidade: os contribuintes e o povo, em geral, se irritam diante das delongas protelatórias, da "paperasserie", e da péssima qualidade da maioria dos serviços públicos. O funcionalismo é considerado parasitário e indigno de tratamento salarial condigno face aos baixos coeficientes de produtividade vigentes.

\section{De quem a culpa?}

No entanto, atribuir ao funcionalismo a culpa pela situação em que se encontra - sem horizontes, sem abertura, sem perspectivas, condenado à estagnação e ao desespêro - é perpetrar um daqueles sofismas da velha lógica vestibular: ignoratio elenchi.

A responsabilidade exclusiva é das chefias encasteladas nos cargos de comando para os quais não estão devidamente preparadas, quer pela falta de qualificação universitária, quer pelas próprias deficiências decorrentes dessa vulnerabilidade. A experiência universal aí está para comprovar a periculosidade da incompetência profissional que, dia a dia, se agrava com uma pletora de conotações psicológicas negativas dentre as quais a menor, mas não menos nefasta, é a mentalidade cartorial, rotineira, emparedada.

Os chefes e seus assessôres é que são os culpados: em hipótese alguma os servidores ressentidos e marginalizados 
numa sociedade de consumo que os relega à condição de simples peças da complicada engrenagem governamental.

A valorização da função pública, inserida nos textos legais e objeto de periódicas reivindicações afigura-se para a imensa maioria dos servidores uma abstração irrealizável.

Mas, à medida em que se fôr acelerando a execução de um planejamento estratégico da administração de pessoal no contexto do desenvolvimento global do País - aquêle ideal de valorização ganhará perspectivas de viabilidade.

Gradualmente, processar-se-á o reconhecimento objetivo da sua real importância. Para êsse fim espera-se uma contribuição concreta do SIPEC, objetivando a reabilitação dos "burocratas" que o Prof. J. C. de Oliveira Tôrres, Superintendente do INPS em Minas Gerais, equacionou em breves palavras carregadas de simplicidade e clareza:

\section{Reabilitação dos burocratas}

“... nas oficinas de trabalho administrativo, o funcionário é sempre obscuro e quase anônimo construtor do Bem Comum.

Pode parecer a muitos monótona ou rotineira a nossa tarefa: o têrmo "burocrático" apresenta colorido pejorativo e não faltam os que negam qualquer valor a nosso trabalho. Mas, se considerarmos os efeitos positivos da ação estatal, seja em que ponto venham a se exercer, devemos ter sempre em vista que, em todos os casos, as leis e planos oficiais se transformam em realidade graças ao trabalho do servidor público que, silenciosamente, modestamente, obscuramente, faz com que as intenções se mudem em fatos tornando as aspirações populares concretizadas nas medidas governamentais" (João Camillo de Oliveira Tôrres, Superintendente Regional do INPS em Minas Gerais. In JB, Caderno Especial, 28-10-70).

\section{O SIPEC: Um desafio}

O Govêrno Federal, atento ao significado estratégico da política de pessoal no campo da ação administrativa, deu-lhe relêvo excepcional destacando, como um dos seus objetivos prioritários: "A atuação dinâmica e planejada do serviço público federal, criando-se na administração direta, um funcionalismo eficiente e de alto nível técnico, e, na administração indireta, um corpo relativamente estável de administradores de emprêsas, operando em níveis de eficiência pelo menos equivalentes aos do setor privado" (cf. Metas e Bases para a Ação de Govêrno, setembro, de 1970). 
Como se vê, os problemas estão suficientemente equacionados, com diagnósticos precisos que permitem acionar, de imediato, o Sistema incumbido de resolvê-los.

Os caminhos estão iluminados pelas experiências, erros e ensinamentos de passado recente: já começou a contagem regressiva para o desfecho de uma ofensiva definitiva - a hora decisiva da ação, os preciosos minutos dos "decision makers".

Certamente, é muito cedo, ainda, para a formulação de quaisquer prognósticos a respeito do SIPEC: essa é uma tarefa para os arúspices da futurologia.

É lícito, porém, delinear algumas conclusões acêrca dos fatôres e pré-condições imprescindíveis ao pleno êxito do recém-instituído SIPEC ao qual, não sòmente cumpre abrir um crédito de confiança proporcional às dimensões do desafio que representa, como, sobretudo, com êle cooperar, coadjuvando-o no desempenho de sua transcendental missão.

\section{À GUISA DE CONCLUSÕES}

\section{Fortalecimento dos órgãos Periféricos}

Em primeiro lugar, urge promover o revigoramento da capacidade decisória, da autoridade e do prestígio da constelação dos órgãos periféricos - setoriais, seccionais e regionais, do Sistema.

O atrofiamento, a marginalização e o desaparelhamento dos órgãos de pessoal comprometeriam, irremediàvelmente, o próprio destino do Sistema, anulando, de saída, a possibilidade de resultados satisfatórios e a própria capacidade empreendedora do conjunto.

De todos os problemas, o da obtenção de pessoal qualificado é predominante. O velho provérbio “L'Administration ce sont les Hommes" - expressão gaulesa do óbvio administrativo - é axiomático.

Sôbre o assunto, o Prof. Glauco Lessa de Abreu e Silva teceu oportunas considerações enfatizando a temática das chefias: - "A questão da escolha dos diretores de pessoal nos parece, também, muito importante. Um cargo de tal nível de significação e dificuldade exige, efetivamente, a atuação de um especialista, a êsses aspectos de um órgão de direção de pessoal nem sempre têm sido considerados no seu preenchimento. Não estamos pugnando pela substituição dos atuais titulares, mas entendemos que se Ihes deve dispensar a necesSária assistência técnica para que possam integrar-se no funcionamento do sistema, assegurando-se, por êsse modo, continuidade à política estabelecida, e mais, que se deve estabe- 
lecer, daqui por diante, critérios adequados de escolha". ("A Nova Política de Pessoal do Serviço Público - Sua Filosofia e Estruturação", in "Revista do Serviço Público".)

O pronunciamento do Diretor-Geral do DASP é provàvelmente um reflexo de sua experiência como administrador, mas corrobora as pesquisas e ensinamentos mais recentes levados a efeito na órbita das ciências administrativas.

\section{Nem contestação, nem subserviência}

As relações entre os componentes do Sistema, sobretudo a postura dos órgãos setoriais e seccionais, diante do órgão Central, não devem ser jamais contestatárias, emocionais, ou, simplesmente, de uma apática subserviência.

Não há clima nem condições, em um sistema, para projeção de complexo de ressentimento, insubordinação ou inferioridade, sempre que as supostas autoridades "superiores" invoquem princípios de autoridade e hierarquia que são provérbios típicos das organizações lineares e do "establishment". As decisões finais caberão, em qualquer hipótese, à lógica suprema da verdade, aos critérios da evidência, de justiça, do mérito, ou da destinação de utilidade - imperativos do realismo imanente que comanda a existência humana, quer se trate das pessoas, quer das instituições.

Seria de todo inconcebível a esta altura supor que os órgãos periféricos tenham de receber, numa bandeja e em "posição de sentido", diretrizes alienadas, desatualizadas ou distantes do "teatro das operações de combate" - isto é, da situação local e da realidade dos casos concretos.

A observação é procedente, mas nada tem a ver a atual conjuntura do DASP que encontrou no Prof. Glauco Lessa 0 intérprete das transformações necessárias à própria sobrevivência da Instituição (Dec. nং 66.222/70).

\section{Missão do órgão Central}

Quanto ao funcionamento do órgão Central, convém insistir nas suas virtualidades e natureza peculiar como peça, segmento ou parte integrante do Sistema. Pelo fato de ser, ao mesmo tempo, cérebro e dínamo propulsor, não se esgota nessa função o papel eminentemente ancilar, fecundante $e$ germinativo do DASP; quem diz Órgão Central, não quer dizer, necessàriamente, órgão preponderante - ou seja, a regressão à odiosa e superada figura do "carro-chefe" dos préstitos carnavalescos. Mister se faz despojá-lo de quaisquer encargos casuísticos, sendo aconselhável a supressão das responsabilidades executivas dêsse tipo, porventura remanescentes. 
Torna-se imperativo que o DASP se concentre, por inteiro, nas funções inerentes à sua nova e legítima condição de órgão Central, sem quaisquer veleidades de auto-suficiência, inflexibilidade, "liderança" do conjunto, ou hipertrofia das atribuições legais que the foram cominadas.

$\mathrm{Na}$ concepção dos modernos "sistemas", órgãos centrais, setoriais, periféricos são igualmente importantes, mùtuamente correlacionados e interdependentes, colimando finalidades comuns. Até mesmo no teatro moderno a figura dos "canastrões" tende ao desaparecimento; o vedetismo se eclipsou inteiramente diante da crescente importância dos figurantes e "extras", das personagens aparentemente secundárias nos dramas, tragédias e comédias que, de uma hora para outra, se esvaziam de conteúdo e sentido, quando não ocorre a "participação" das audiências perplexas: o verdadeiro espetáculo, na verdade, se distancia cada vez mais dos palcos, dos proscênios, das ribaltas... e se transfere para a realidade do quotidiano.

Num "sistema", a preponderância de qualquer uma das partes componentes sôbre as demais é uma heresia, uma barbaridade conceitual, técnica e operativa. Como num paralelograma de fôrças, o que vale é a resultante final convergente: no caso, a execução de uma política de pessoal sintonizada com a estratégia do desenvolvimento nacional.

\section{Desmitificação}

Não faltará, por certo, ao DASP, a alta compreensão de seu decisivo papel a ser desempenhado com um autêntico "sense de rôle", a máxima humildade e eficiência. Servir. Resistir à embriagante tentação de um protagonismo desmitificado pela psicanálise - isto é, renunciar, deliberadamente, à ilusão das decisões carismáticas e autoritárias - mas efêmeras - pela atuação desglamourizada, modesta e aparentemente humilde - mas saturada de autenticidade, perenidade e utilidade.

\section{Seleção dos mais capazes}

O Decreto n? 67.326/70 sobrecarregou o DASP (art. 13), com o encargo de colaborar na avaliação das condições de capacidade dos indicados ao provimento de cargos ou funções de dirigentes dos órgãos Setoriais e Seccionais.

A escolha dos homens certos, a rejeição dos amadores, dos apaniguados, dos "profiteurs" de feudos domésticos tão comuns nos serviços públicos dos países subdesenvolvidos - a seleção dos melhores ou, pelo menos, dos mais capacitados, em síntese, a constituição de equipes altamente 
qualificadas, mas, indispensáveis, continua sendo o desafio supremo nos domínios escorregadios, fluidos e inconsistentes da administração. Êste é, de resto, um dos problemas vitais do próprio órgão Central de cuja solução dependerá, lògicamente, a harmonia, a integração, a eficiência, a sinergia de todo 0 Sistema.

\section{Racionalidade}

O que importa - menos pelos Sistemas em si do que pela erradicação do subdesenvolvimento administrativo - é consolidar os seus aspectos positivos, aparelhá-lo com os necessários recursos humanos e materiais, fixar-lhe novas metas prioritárias, adaptá-lo às condições e peculiaridades oriundas das transformações revolucionárias que se operam em todos os setores das atividades nacionais, enquadrá-lo num contexto de racionalidade e aperfeiçoamento permanente.

\section{Trilogia}

Aliás, na totalidade dos países, a detecção, busca e aproveitamento do homem com qualificações especificas é o ponto de convergência de qualquer planejamento, a incógnita maior, a meta colimada. Em segundo lugar, situa-se a organização adequada - cenário da atuação do homem qualificado como pesquisador, dirigente ou apenas "mão-de-obra", o indispensável "skilled labor"; finalmente, a serviço de ambos, os modernos sistemas informáticos, representados pelos computadores, que são, ao mesmo tempo, instrumentos e símbolos de uma etapa preponderantemente tecnológica da civilização contemporânea. A trilogia "homem qualificado - organização racional - computador" se apresenta como o fulcro dos "sistemas". ("São os pilares da eficácia administrativa" na expressão do Técnico de Administração Mário Lopes.) (In R.S.P. vol. 105, n? 2-1970.)

Mesmo dispondo de computadores e dos mais avançados equipamentos eletrônicos as organizações se deterioram quando as equipes dirigentes não são suficientemente qualificadas. A ineficiência administrativa compromete, retarda $e$ anula qualquer programação. Nenhum órgão resiste às chefias incompetentes que, na bocejante rotina burocrática, mantêm um simulacro de atividade. As repartições estão cheias de pessoal que, na direção ou execução dos serviços, exibem uma aparência de "trabalho" cujos resultados ninguém conhece:... É o festival das nulidades empavonadas, estigmatizadas pelo anedotário popular, mas responsáveis pela visão deformada do funcionalismo público como expressão do parasitismo e da incompetência. 


\section{Estratégia}

A Comissão de Coordenação (Art. 9, Decreto n 67.326/70) promoverá "la mise-en-marche" do Sistema e obviará as possíveis falhas e omissões que forem reveladas pela experiência de funcionamento. No elenco de suas atribuições destaca-se, naturalmente, a de elaborar a planificação estratégica de uma verdadeira política de pessoal adequada às necessidades brasileiras em função daquele "Objetivo-Síntese" - a que se fêz referência no início destas notas - ou seja, um documento básico contendo os objetivos prioritários, os recursos que permitirão alcançá-los e a metodologia que possibilitará a execução da política global de acôrdo com um cronograma rigorosamente preparado.

\section{Tática}

Em seguida, cumpre estabelecer a Coordenação Tática das providências a serem tomadas a curto prazo, segundo critérios decorrentes da análise do Sistema, viabilidade, funcionalidade, custos e diretrizes técnicas de ordem jurídica, econômica e administrativa. É a fase da programação operativa, que proporcionará ao Sistema objetividade e segurança, assegurando a obtenção de metas preestabelecidas - sempre que possivel quantificadas.

À Comissão de Coordenação cabe o encargo de, no conjunto das providências táticas, promover, de imediato:

1) Uma radical sistematização, simplificação e, por assim dizer, "cibernetização" da instrumentalidade juridica que se traduz em têrmos de uma legislação inflacionada, perturbadora e conflitante;

2) A mecânica de funcionamento do Sistema, prevendo a progressiva implantação, nos setores adequados que o permitam, das mais avançadas técnicas de processamento automatizado de dados (ADP - "automated data processing"), cujas vantagens são universalmente reconhecidas e pouco a pouco vão substituindo os "processos" tradicionais, contribuindo, destarte, para erradicação do subdesenvolvimento administrativo.

\section{Avaliação do Desempenho}

Finalmente, carece o Sistema de processos originais de contrôle operativo que possibilitem acompanhar a execução da política de pessoal e avaliar o desempenho global e setorial dos órgãos que o integram. É a fase de correção dos desajustamentos observados, mensuração das atividades e verificação dos resultados obtidos, pelo Sistema, em têrmos de eficácia e eficiência: conceitos que C. Barnard diferenciou e definiu com 
rigor técnico (no clássico "The Functions of the Executive", Cambridge Harvard University Press, 1938).

NOTA: - Além dos sistemas prioritários para a administração do desenvolvimento - acêrca dos quais tentamos resumir alguns conceitos nesta breve colaboração ora divulgada pela RSP - ou seja, os Sistemas de planificação, orçamento, contabilidade, auditoria, tributaçấo, modernização administrativa (O\&M), pessoal, estatística, abastecimento e informática -, surgiu, no Brasil, como uma inovação radical, o mais moderno e complexo dos Sistemas: o de Comunicação Social do Poder Executivo. Sôbre o assunto, preparamos um artigo a ser publicado em um dos próximos números da Revista do Serviço Público. O nôvo Sistema a que nos referimos foi instituído pelo Decreto n? 67.611, de 19-10-70.

\section{DECRETO № 67.611, DE 19 DE NOVEMBRO DE 1970}

Estabelece o Sistema de Comunicação Social do Poder Executivo, e dá outras providências.

O Presidente da República, usando das atribuições que the confere o artigo 81 , inciso III, da Constituição, decreta:

Art. 19- Fica instituído, nos moldes do artigo 30 do Decreto-lei no 200, de 25 de fevereiro de 1967, o Sistema de Comunicação Social do Poder Executivo.

$\$ 10$ - Integram-se ao Sistema de que trata êste artigo a Assessoria Especial de Relações Públicas da Presidência da República, os órgãos de Relações Públicas dos Ministérios e do Estado-Maior das Fôrças Armadas, bem como os órgãos similares da Administração Indireta.

\$ 2 ? - A Assessoria Especial de Relaçöes Públicas da Presidência da República compete exercer as funções de órgão central do Sistema instituído por êste Decreto.

Art. 2 ? - Cabe ao Sistema de Comunicação Social do Poder Executivo o encargo de formular e aplicar a Política capaz de, no campo interno, predispor, motivar e estimular a vontade coletiva para o esfôrço nacional de desenvolvimento e, no campo externo, contribuir para o melhor conhecimento da realidade brasileira.

Art. 3 ? - Este Decreto entrará em vigor na data de sua publicação, revogadas as disposições em contrário. República.

Brasilia, 19 de novembro de $1970 ; 149$ a Independência e $82^{\circ}$ da

EMÍLIO G. MÉDICI

Alfredo Buzaid

Adalberto de Barros Nunes

Orlando Geisel

Mário Gibson Barboza

Antônio Delfim Netto

Mário David Andreazza

L. F. Cirne Lima

Jarbas G. Passarinho

Júlio Barata

Márcio de Souza e Mello

F. Rocha Lagôa

Marcus Vinicius Pratini de Moraes

Antônio Dias Leite Júnior

João Paulo dos Reis Velloso

José Costa Cavalcanti

D.o. de 19-11-70

Hygino C. Corsetti 


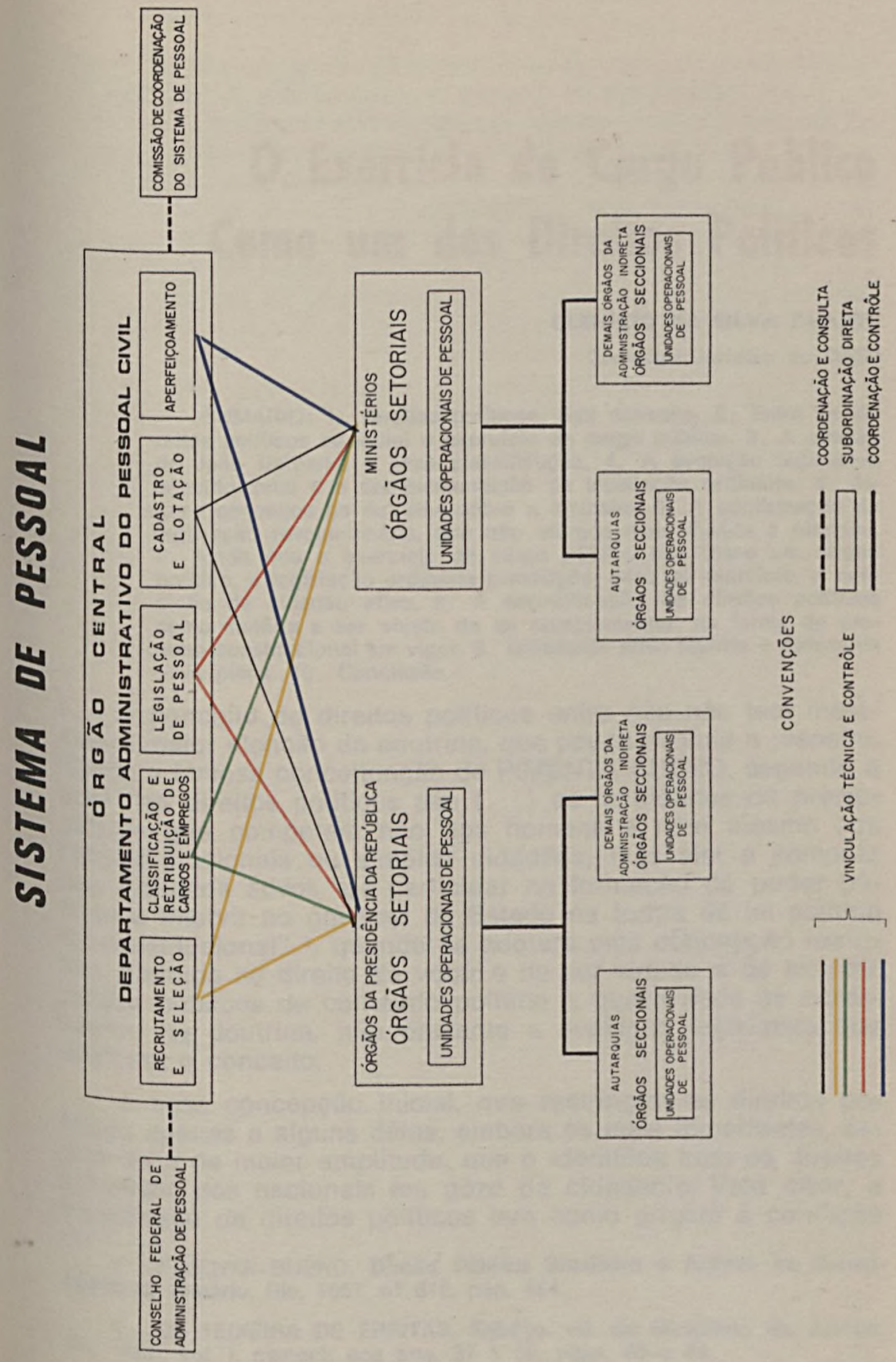


